\title{
ARTIGO
}

\section{GESTÃO DOS RECURSOS VOLTADOS À EDUCACÃO ESPECIAL EM MUNICÍPIO BRASILEIRO (2008-2014)}

\author{
Marileide Gonçalves França* \\ Universidade Federal do Espírito Santo (UFES), Vitória - ES, Brasil \\ Rosângela Gavioli Prieto** \\ Universidade de São Paulo (USP), São Paulo - SP, Brasil
}

RESUMO: Esse texto busca discutir o financiamento da educação especial no Brasil, tema pouco difundido nessa área e relacionado à melhoria da qualidade do ensino, com vista a analisar os esforços do poder público municipal no provimento de recursos para essa modalidade de ensino, no período de 2008-2014, com base em fontes documentais. Adota concepção de Estado com apoio em Poulantzas (2000) e suas implicações para a gestão pública e também bases referenciais de financiamento e educação especial.O município empreendeu esforços na tentativa de garantir o direito à educação para todos, por meio de políticas e serviços oferecidos na sua rede de ensino. Contudo, os valores irrisórios previstos para essa modalidade estavam subdimensionados e/ou agregados às outras etapas de ensino.

Palavras-chave: Educação especial. Financiamento. Gestão pública. Vitória.

\section{RESOURCES MANAGEMENT FOR SPECIAL EDUCATION IN A BRAZILIAN MUNICIPALITY (2008-2014)}

ABSTRACT: Based on documental research, this text aims at discussing the funding for Special Education in Brazil, a theme not widespread in this area and related to the improvement of the quality of education, by analyzing the efforts of public municipal authorities to provide resources to this teaching modality, in the period of 2008-2014. The study adopts the concept of State based on Poulantzas (2000) and its implications to public management as well as to the referential basis for the financing for special education.The municipality authority has made an effort to ensure the right to education for all through policies and services offered in its school network. However, the derisory values foreseen for this modality were underestimated and/or added to the other stages of teaching system.

Keywords: Special Education. Funding. Public management. Vitória.

"Doutor em Educação pela Universidade de São Paulo (USP). Professor e pesquisador do Programa de PósGraduação em Ensino, Educação Básica e Formação de Professores da Universidade Federaldo Espírito Santo (UFES). E-mail:<marileide.franca@ufes.br > .

"Doutor em Educação pela Universidade de São Paulo (USP). Professor e pesquisador do Programa de Pós-graduação em Educação da Faculdade de Educação da USP. Coordenadora do grupo de pesquisa do CNPq: Políticas de Educação Especial. E-mail:<rosangel@usp.br > . 


\section{INTRODUC̣ÃO}

As políticas educacionais implementadas pelo Estado brasileiro, desde a Constituição Federal (BRASIL, 1988, 1996a, 1996b, 2006a), têm engendrado transformações na educação brasileira.

Pesquisas realizadas nas últimas décadas (VIEIRA, 2009; DOURADO, 2007), referentes às políticas públicas de educação, mostram que houve significativas transformações nessa área no Brasil, seja na sua organização ou expressas tanto na base legal, produzida a partir do processo de redemocratização do país, como por assumirem diferentes configurações de gestão e financiamento. Entretanto, a compreensão desses processos não se restringe a aspectos educacionais; articula-se a um contexto mais amplo de transformações econômicas, sociais e políticas.

A gestão pública, área responsável pela planificação e materialização das políticas públicas, integra diferentes dimensões, entre as quais as apontadas por Vieira (2009, p. 24): “[...] o valor público, as condições de implementação e as condições políticas", o que, por sua vez, pressupõe intencionalidade, disponibilidade de recursos financeiros e humanos e outras condições materiais e imateriais, além de circunstâncias políticas que envolvem, na tomada de decisões, negociações e administração de conflitos de interesses, que, por vezes, são distintos ou até mesmo antagônicos. Segundo Vieira e Albuquerque (2002, p. 26), é “[...] na correlação de forças entre os atores sociais das esferas do Estado - a sociedade política e civil que se definem as formas de atuação prática, as ações governamentais e, por conseguinte, se trava o jogo das políticas sociais".

Faz-se necessário destacar que as ações desencadeadas em diferentes sistemas ou redes de ensino são influenciadas por orientações, compromissos e perspectivas de políticas mais amplas, formuladas e/ou implantadas em nível federal ou presentes em tratados e recomendações internacionais; por isso, seus princípios e/ou ações podem ser assimilados, total ou parcialmente, pelos gestores de políticas públicas em âmbito local. Para Dourado (2007, p. 922), isso "[...] implica não reduzir a análise das políticas e da gestão educacional à mera descrição [...] importando, sobremaneira, apreendê-la no âmbito das relações sociais em que se forjam as condições para sua proposição e materialidade".

Nas investigações na área de educação especial a discussão predominante é sobre práticas escolares, pois ainda são incipientes as produções e os debates que abordam as condições de sua implantação, especialmente as que tratam do financiamento de ações nesta área. 
Gomes e Sobrinho (1996) e Prieto (2009, p. 5) corroboram essa avaliação e, segundo esta autora, "[...] ainda pouco se têm divulgado análises sobre a gestão pública da educação especial em municípios e é particularmente exíguo o conhecimento sobre as formas de financiamento público adotadas para garantir o atendimento especializado".

Outros estudos, mesmo tratando sobre financiamento da educação especial (CARDOSO, 1997; CORRÊA, 2008; BENATTI, 2011; VIEGAS, 2014), dedicam sua atenção, prioritariamente, para a dimensão público-privada, com foco ora nas parcerias do Estado com as instituições especializadas, ora nos serviços ofertados, ora nos recursos destinados às instituições públicas não estatais de educação especial. Poucas pesquisas voltam-se ao estudo do financiamento da educação especial no âmbito dos municípios, de modo a analisar o esforço do Poder Público no provimento de recursos voltados a essa modalidade de ensino. Nosso estudo estabeleceu-se nessa direção, na tentativa de discutir o financiamento da educação especial em um sistema municipal de ensino.

Nesse sentido, analisar as políticas públicas da educação especial implica em averiguar as formas de aplicação dos recursos em educação, na medida em que estes podem possibilitar a ampliação das matrículas e o fomento à melhoria da qualidade de ensino para todos os cidadãos.

Este texto discute o financiamento da educação especial em um município brasileiro, destacando aspectos relacionados à gestão pública dos recursos, com vista a analisar os esforços do poder público no provimento de recursos para essa modalidade de ensino, no período de 2008 a 2014. O período considerado compreendeu o ano de 2008, pois considera as mudanças ocorridas com o novo padrão de financiamento da educação adotado com a implantação do Fundo de Manutenção e Desenvolvimento da Educação Básica e de Valorização dos Profissionais da Educação (Fundeb) em 2007, que passou a abranger todas as etapas e modalidades de ensino; e as alterações na legislação da educação especial, com a promulgação da Política Nacional de Educação especial na Perspectiva da Educação Inclusiva- PNEE-EI (BRASIL, 2008); e o ano de 2014, último ano de dados consolidados nos balanços do município, no período da pesquisa.

No contexto atual de expansão de matrículas da educação especial, é fundamental ampliar conhecimentos sobre financiamento e gestão dos recursos educacionais para garantir aos alunos com deficiência, Transtornos Globais de Desenvolvimento (TGD) e altas habilidades/superdotação melhoria da qualidade da educação.

Este artigo é apresentado em duas seções, além desta introdução e das considerações finais. Primeiramente, discorre-se sobre o entrecruzamento de gestão de recursos públicos e políticas de 
educação especial no Brasil e seu financiamento. A segunda apresenta os resultados a partir da caracterização do município pesquisado e dos dados de despesas destinados à educação especial.

\section{GESTÃO DAS POLÍTICAS PÚBLICAS DE FINANCIAMENTO DA EDUCAÇÃO ESPECIAL NO ÂMBITO DO ESTADO BRASILEIRO}

Partimos do pressuposto que as políticas de financiamento e sua gestão sofrem influência das correlações de forças políticas, econômicas e sociais em torno da disputa pelo fundo público, no âmbito do Estado brasileiro, marcado pelas contradições e interesses de diferentes grupos e classes que estão presentes ou podem interferir nos processos de formulação e implementação das políticas educacionais.

Para Poulantzas (2000, p. 130), o Estado se configura como uma "[...] relação, mais exatamente como a condensação material de uma relação de forças entre classes ${ }^{1}$ e frações de classe ${ }^{2 "}$, isto é, como um espaço de disputa de poder, no qual estão em jogo diferentes interesses, o que possibilita, segundo o autor, compreender as funções diferenciadas que o Estado desempenhou em cada contexto histórico-social específico. No âmbito da discussão e definição sobre financiamento da educação especial(KASSAR, 2001; MAZZOT'TA, 2011; FERREIRA, 2005), observamos que as políticas são formuladas nesse campo de correlações de forças que envolvem familiares, movimentos sociais nacionais e internacionais, profissionais da educação, representantes políticos e sujeitos implicados diretamente nessas questões e de instituições privadas de educação especial que, em nome da manutenção, efetivação e ampliação dos seus direitos, podem defender diferentes propostas em distintos momentos históricos sobre a aplicação de recursos públicos. Dessa maneira, tais embates permeiam a estrutura do Estado e interferem na formulação das políticas, que, por sua vez, são "resultantes das contradições de classe inseridas na própria estrutura do Estado" (POULANTZAS, 2000,p.134), isto é, de relações de forças e resistências que fazem do Estado uma expressão condensada da luta de classes.

No Brasil, a trajetória histórica da educação especial iniciou-se atrelada às ações isoladas, desenvolvidas no Ministério da Educação e Cultura, primeiramente para criação de instituições especializadas federais e, na sequência, de cessão de aportes voltados à instalação, manutenção e expansão de instituições privadas de caráter assistencial, inaugurando um período de aplicação de verbas públicas da educação, da saúde e/ou da assistência social, no setor privado, nesse caso de 
natureza filantrópica.Somente no final dos anos 1950 e início da década de 1960 o Estado brasileiro começa a assumir a educação especial como política pública, mas não sem manter o financiamento a serviços privados (MAZZOT'TA, 2011).

A expansão acentuada das matrículas na classe comum (a partir do final da década de 1990) se deu num processo de reconfiguração das funções do Estado e das políticas sociais, no âmbito do neoliberalismo, revelando o caráter contraditório em que se estabelece o financiamento da educação especial nesse momento no capitalismo, no qual assistimos o distanciamento do Estado das suas responsabilidades sociais e, ao mesmo tempo, a expansão das políticas direcionadas ao público-alvo da educação especial, a partir da destinação de mais recursos públicos para a implantação de programas federais ${ }^{3}$ para dar suporte à inclusão escolar ${ }^{4}$. Historicamente, segundo Ferreira (2009), os parcos recursos voltados a essa modalidade de ensino eram dirigidos mais às instituições filantrópicas que tinham centralidade na política e na gestão da educação especial.

Assim, o financiamento da educação especial sempre foi disputado por diferentes forças econômicas e sociais que, por sua vez, interferem na constituição de políticas públicas. Segundo Gomes e Sobrinho (1996), os processos decisórios sobre os recursos financeiros constituem, em geral, arenas de competição e conflitos incessantes entre diferentes atores sociais, com interesses diversos. No caso da educação especial, nesse jogo de correlações de forças no âmbito do orçamento do Estado, há disputas por recursos entre as diferentes etapas e modalidades de ensino e entre o Poder Público e as entidades privadas pela manutenção de sua participação no fundo público.

Nesse contexto, a disputa entre o público e o privado, no âmbito do Estado, envolve o ordenamento jurídico normativo e os elementos que compõem o sistema de financiamento da educação no Brasil, ou seja, um conjunto de normas constitucionais que regulam o gasto da receita tributária ${ }^{5}$, certo número de fontes de receita vinculadas a gastos com educação e uma estrutura burocrática complexa baseada na centralização de arrecadação de recursos e na descentralização da responsabilidade das despesas (FARENZENA, 2006).

Em 1988, quando tivemos a aprovação da Constituição Federal (CF/88), ficou estabelecido, no art. $6^{\circ}$, o direito à educação, como direito público subjetivo e o detalhamento dos aspectos relacionados à sua concretização, tais como os seus princípios e objetivos, os deveres de cada ente da federação, a estrutura educacional, além de um sistema próprio de financiamento que prevê a vinculação constitucional de recursos (BRASIL, 1988). 
Essa Carta Magna introduz a ideia de que essa é tarefa a ser compartilhada entre Estado e sociedade (BRASIL, 1988, art. 205) e, nessa perspectiva, o Estado, entendido aqui como Poder Público, tem a responsabilidade de oferecer a educação em todos os níveis e modalidades de ensino aos cidadãos brasileiros.

O financiamento da educação na CF/1988 caracterizouse pela orientação da descentralização financeira, representando o aumento da participação dos estados e municípios na arrecadação tributária e nas receitas disponíveis. O percentual de verbas vinculadas à educação atribuída à União foi elevado para "nunca menos de dezoito, e os Estados, o Distrito Federal e Municípios vinte e cinco por cento, no mínimo, da receita resultante de impostos, compreendida a proveniente de transferências, na manutenção e desenvolvimento do ensino" (BRASIL, 1988, art. 212). Assim, observamos transformações significativas no que tange ao âmbito jurídico-institucional, representadas pelas políticas de reestruturação de gestão, organização e financiamento da educação básica ao longo da década de 1990, que trouxeram implicações para a configuração das etapas e modalidades de ensino nos entes federados.

No que se refere à educação especial, de acordo com Ferreira (2005, p. 62), com o processo de redemocratização e com a atuação propositiva dos movimentos sociais no contexto da Constituinte (1987-1988), comprometidos com a universalização do acesso e a democratização do ensino básico público, surgiram inúmeras críticas em relação às práticas de identificação e categorização e consequente segregação das pessoas com deficiência em instituições especializadas ou classes especiais, assim como questionamentos sobre a quem deveria caber a responsabilidade desse atendimento até então realizado, predominantemente, em instituições privadas, e também discussões sobre os modelos homogeneizadores de ensino e aprendizagem e a exclusão dessa população dos espaços escolares.

Essas críticas se aliavam aos pressupostos dos movimentos locais e internacionais pela educação inclusiva, que questionavam a natureza segregadora e marginalizadora dos ambientes exclusivos de ensino especial. Desse modo, as demandas relacionadas à educação das pessoas com deficiência, TGD e altas habilidades/superdotação começaram a ganhar visibilidade nas políticas educacionais como resultado desse processo de luta pelo reconhecimento e consolidação dos seus direitos sociais. Aqui mais uma vez destaca-se o papel de pressão da sociedade civil no âmbito do Estado. 
Nessa perspectiva, a CF/1988 estabelece como direito, no art. 208, inciso III, o "atendimento educacional especializado aos portadores de deficiência, preferencialmente na rede regular de ensino" (BRASIL, 1988). Cabe ressaltar, a manutenção, no âmbito dessa Constituição, pelo art. 213, da possibilidade de autorização para que sejam utilizados convênios com entidades da sociedade civil para complementar os atendimentos de supracitado público. Dessa maneira, observamos que a responsabilidade pelo atendimento a essaspessoas continua a ser compartilhada com a sociedade civil, aspecto observado em toda a história da educação especial brasileira (KASSAR, 2001).

$\mathrm{Na}$ Lei de Diretrizes e Bases da Educação Nacional, Lei n ${ }^{\circ} 9.394$ de 20 de dezembro de1996 (LDB/96), foi estabelecido o dever do Estado com a educação, mediante a garantia de "padrões mínimos de qualidade de ensino, definidos como a variedade e quantidade mínimas, por aluno, de insumos indispensáveis ao desenvolvimento do processo de ensinoaprendizagem" (BRASIL, 1996a, art. $4^{\circ}$, inciso IX). Essa ideia se articula à necessidade de investir esforços no intuito de garantir a universalização da educação e melhores condições de ensino. No Brasil, o padrão de qualidade está relacionado aos recursos mínimos disponibilizados pela vinculação constitucional e ao valor aluno-ano definido pela política de fundos (PINTO; ADRIÃO, 2006; OLIVEIRA, 2007).

Nessa direção, a educação foi ratificada como tarefa compartilhada entre União, Distrito Federal, estados e municípios, sendo organizada sob a forma de regime de colaboração (CF/88, art. 211 e LDB/96, art. $8^{\circ}$ ). Cada instância é responsável pela administração, expansão e manutenção dos seus respectivos sistemas de ensino, incluindo a organização de políticas e programas voltados à educação especial. Farenzena (2006, p. 99) destaca que "o reconhecimento dos órgãos executivos do setor educacional das três esferas do governo como gestores dos recursos pode possibilitar uma administração mais eficaz e efetiva dos recursos orçamentários". No âmbito da LDB/96 (BRASIL, 1996, art. $8^{\circ}$ ), ainda foi enfatizado o papel coordenador e articulador da União em relação aos demais entes federados, tendo como uma das suas tarefas a responsabilidade pelos diferentes níveis e sistemas de ensino, exercendo função normativa, redistributiva e supletiva em relação às demais instâncias educacionais.

A educação especial, nesse cenário, apresentou avanços em termos de legislação e também sofreu implicações na sua organização e financiamento. A LDB/96, ao estabelecer a educação especial como modalidade de educação escolar, prevê:

$\S 1^{\circ}$ Haverá, quando necessário, serviços de apoio especializado, na escola regular, para atender às peculiaridades da clientela de educação especial. 
$\int 2^{\circ} \mathrm{O}$ atendimento educacional será feito em classes, escolas ou serviços especializados, sempre que, em função das condições específicas dos alunos, não for possível a sua integração nas classes comuns de ensino regular (BRASIL, 1996a, art. 58).

Desse modo, essa Lei garante dois tipos de serviços: de apoio especializado, oferecidos em paralelo àqueles matriculados na classe comum, e o atendimento educacional realizado em classes, escolas ou serviços especializados (BRASIL, 1996a). Cabe destacar que a redação desse dispositivo admite a possibilidade de substituição do ensino regular pelo especial. Contudo, para manter coerência com a perspectiva inclusiva adotada pela política educacional brasileira é imprescindível assumir o disposto na $\mathrm{CF} / 88$ que garante a obrigatoriedade da educação básica pública e gratuita a todo cidadão brasileiro, de quatro a dezessete anos, e a todos os que a ela não tiveram acesso em idade própria (BRASIL, 1988, art. 208). Desse modo, a LDB/96 faz referência à educação especial como modalidade que perpassa todas as etapas da educação básica e a superior e as demais modalidades de ensino; portanto, com vista a consolidar os propósitos da inclusão escolar a interpretação conferida à LDB/96 é a de que o acesso a serviços de educação especial, previstos nos art. 58 e 59, não podem substituir o direito à educação oferecida em classe comum (BRASIL, 2004a).

Entretanto, no art. 60dessa Lei, está reafirmado o compromisso do Estado em oferecer essa modalidade de ensino a partir do apoio técnico e financeiro às instituições privadas sem fins lucrativos, ressaltando a relação contraditória entre Poder Público e privado na história da educação especial, na política educacional e no financiamento público. Nos termos da Lei, está assim estabelecido:

Os órgãos normativos dos sistemas de ensino estabelecerão critérios de caracterização das instituições privadas sem fins lucrativos, especializadas e com atuação exclusiva em educação especial, para fins de apoio técnico e financeiro pelo poder Público.

Parágrafo único: o poder Público adotará, como alternativa preferencial, a ampliação do atendimento aos educandos com deficiência, TGD e altas habilidades/ superdotação na própria rede pública regular de ensino, independentemente do apoio às instituições previstas neste artigo (BRASIL, 1996a).

Mas, atenção especial deve ser dada ao Parágrafo único, pois neste o Estado deve assegurar a ampliação do atendimento na rede regular de ensino, em classe comum, independentemente do apoio às instituições privadas, um compromisso inédito no âmbito da lei 
nacional brasileira sobre educação. Na trajetória da educação especial no Brasil, Bueno e Kassar (2005) evidenciaram que, a história da educação especial seria exemplar do processo de publicização proposto pelo governo federal a partir da reforma do Estado, da década de 1990, uma vez que o financiamento por parte do Poder Público às instituições não governamentais e filantrópicas, tais como as unidades da Associação de pais e amigos dos excepcionais (Apae) e da Associação Pestalozzi, bem como a outras inúmeras instituições especializadas que mantêm convênios com secretarias estaduais e municipais de educação, tende a se fortalecer em contexto de distanciamento do Estado com relação às políticas públicas.

Desse modo, o Poder Público atua, diretamente, tanto na oferta de serviços de educação especial, como no repasse de verbas a essas instituições, que podem conjugar várias fontes de receitas, públicas e/ ou privadas, na prestação de seus serviços. Nesse contexto, as diretrizes educacionais estabelecidas pela LDB/96 e, posteriormente, a Resolução $\mathrm{n}^{\circ} 2$, de 11 de setembro de 2001(BRASIL, 2001), que instituiu as Diretrizes Nacionais para a Educação Especial na Educação Básica, embora afirmem a importância de atendimento das necessidades do alunado da educação especial na escola comum, respaldam a manutenção do caráter substitutivo da educação especial, na medida em que conserva "a possibilidade do atendimento educacional especializado substitutivo à escolarização" (BRASIL, 2015, p. 9).

Diante desse contexto, Garcia e Michels (2011) afirmam que, ao longo do século XX, a educação especial foi estruturada em poucas instituições públicas e em rede paralela de instituições privadas, que desenvolveram o seu trabalho em regime de convênios e parcerias com as secretarias de educação de estados e municípios. Já, no início do século XXI, há um movimento claro de intervenção estatal na política educacional no que se refere à educação do público-alvo da educação especial, por meio “[...] da presença do Estado na criação de equipamentos públicos de educação especial” (GARCIA; MICHELS, 2011, p. 116), nas redes de ensino estaduais e municipais.

Pode corroborar essa perspectiva de expansão e serviços a instituição dos fundos voltados ao financiamento da educação como o Fundo de Manutenção e Desenvolvimento do Ensino Fundamental e de Valorização do Magistério ${ }^{6}$ (Fundef), instituído pela EC/1996, e regulamentado pela Lei ${ }^{\circ} 9.424$, de 24 de dezembro desse mesmo ano (BRASIL, 1996c), tendo vigorado até o ano de 2006. No tocante à educação especial, o Fundef estabeleceu a definição de um valor 
mínimo por aluno-ano diferenciado do valor mínimo nacional, de acordo com o nível de ensino e o tipo de estabelecimento, que levasse em conta o custo por aluno (BRASIL, 1996c). Vale ressaltar que, até 1999, não houve nenhum tipo de diferenciação de valores nos custos do Fundef em relação aos estabelecidos para todas as etapas e modalidades de ensino; de 2000 a 2004, estipulou-se um acréscimo de $5 \%(1,05)$ para alunos de $5^{\mathrm{a}}$ a $8^{\mathrm{a}}$ séries e da educação especial, superior ao definido para o das séries iniciais urbanas do ensino fundamental $(1,00)$ (FERREIRA, 2009). Cumpre acrescentar que, em 2004, o governo federal como medida paliativa, criou o Programa de Complementação no Atendimento Educacional Especializado às Pessoas Portadoras de Deficiências (Paed ${ }^{7}$ ), por meio da Lei $\mathrm{n}^{0} 10.845$, de 5 de março de 2004 (BRASIL, 2004b).Desse modo, por meio do Paed, as instituições privadas de educação especial garantiram participação no fundo público federal para manutenção e funcionamento de suas atividades, para além dos recursos que já recebiam dos estados e municípios por meio de convênios, para a oferta de serviços ao alunado da educação especial. Em 2005, nova diferenciação elevou o referido fator de ponderação para $7 \%(1,07)$, com o Decreto $n^{\circ}$ 5.374, de 17 de fevereiro (BRASIL, 2005a).

O Fundeb, criado pela Emenda Constitucional n ${ }^{\circ}$ 53/2006 e regulamentado pela Lei $\mathrm{n}^{\circ} 11.494$, de 20 de junho de 2007(BRASIL, 2007a) e pelo Decreto n ${ }^{\circ}$ 6.253, de 13 de novembro de 2007 (BRASIL, 2007b), em substituição ao Fundef, garante que a maior parte dos recursos vinculados à educação seja aplicada na educação básica, por meio de seu mecanismo de distribuição com base no número de alunos das diversas etapas e modalidades de ensino, informado no Censo Escolar do ano anterior, sendo computados os estudantes matriculados nos respectivos âmbitos de atuação prioritária (art. 211 da CF/1988). Na versão final do Fundeb, foram acrescentadas as matrículas de educação infantil e da educação especial da rede conveniada sem fins lucrativos, revigorando a participação de verba pública no setor privado.

Em 2008, foi publicado o documento "Política Nacional de Educação especial na Perspectiva da Educação Inclusiva" - PNEEEI/2008 - (BRASIL, 2008a), que passou a orientar os sistemas de ensino para a organização de serviços e recursos de educação especial. O objetivo é promover respostas às necessidades educacionais especiais dos alunos com deficiência, TGD e altas habilidades/ superdotação. Essas respostas devem contemplar a proposta pedagógica da escola. Tal concepção se contrapõe à caracterização que a educação especial vem assumindo ao longo da história no que 
diz respeito à estrutura e à forma de atendimento em substituição à escolarização de seu público em classe comum. A perspectiva do documento é que a ampliação de recursos e serviços complementares e suplementares provoque o deslocamento de todas as matrículas de serviços exclusivos para unidades de ensino comum.

No intuito de garantir a implementação da PNEE-EI/08, o Decreto $\mathrm{n}^{\circ}$ 7.611, de 17 de novembro de 2011 (BRASIL, 2011) foi aprovado em substituição ao Decreto n. ${ }^{\circ} 6.571$ (BRASIL, 2008), com a finalidade de garantir o compromisso da União na prestação de apoio técnico e financeiro aos sistemas públicos de ensino do Distrito Federal, dos estados e dos municípios, e às instituições comunitárias, confessionais ou filantrópicas sem fins lucrativos, para a ampliação da oferta do atendimento educacional especializado.

Assim, a partir de 2010, os alunos com deficiência, TGD e altas habilidades/superdotação passaram a ser contabilizados duplamente no âmbito do Fundeb, quando matriculados em classes comuns do ensino regular e também no atendimento educacional especializado, podendo este ser realizado na mesma escola que o aluno frequenta, em outra do seu entorno, ou por instituições comunitárias, confessionais ou filantrópicas sem fins lucrativos, que prestem esse tipo de serviço, pela via do dispositivo acrescido ao Decreto n ${ }^{\circ}$ 6.253/2007 (BRASIL, 2007b) que dispõe sobre o Fundeb.

Cabe destacar, ainda, que os princípios definidos na atual política do governo federal (BRASIL, 2008, 2009, 2011) foram confirmados, em 2010, pela Conferência Nacional de Educação (Conae), que mobilizou, no território nacional, diferentes grupos sociais na discussão de diretrizes e estratégias para a construção de um novo Plano Nacional de Educação (PNE) (LAPLANE; PRIETO, 2010). Os debates na Conae (2010) resultaram em um documento final com análises, diretrizes, metas, ações e estratégias que serviram de base para a composição do Projeto Lei no 8.035, de 20 de dezembro 2010 (PL/2010), que tratava da aprovação do novo PNE, de autoria do Poder Executivo. O PL/2010 (BRASIL, 2010) foi discutido na Câmara dos Deputados e encaminhado ao Senado que elaborou Emenda/Substitutivo ao Projeto da Lei da Câmara $\mathrm{n}^{\circ}$ 103, de 25 de outubro de 2012 (BRASIL, 2012). O Documento Substitutivo foi aprovado pela Comissão Especial da Câmara dos Deputados, que teve como relator o Senador Angelo Vanhoni (PTPR), o qual assegurou a inclusão no texto de que recursos públicos pudessem ser destinados às instituições privadas de ensino para efeito de contabilização dos 10\% do PIB (BRASIL, 2012). 
Após quase quatro anos de tramitação entre o MEC e o Congresso Nacional, o PNE foi aprovado pela Lei no 13.005 , de 25 de junho de 2014, com 14 artigos, 20 metas e 254 estratégias, os quais, durante os próximos 10 anos, orientarão as diretrizes e as políticas educacionais. No PNE (2014-2024), a educação especial foi contemplada na Meta 4, cujo compromisso assumido para o decênio é:

[...] universalizar, para a população de 4 (quatro) a 17 (dezessete) anos com deficiência, transtornos globais do desenvolvimento e altas habilidades ou superdotação, o acesso à educação básica e ao atendimento educacional especializado, preferencialmente na rede regular de ensino, com a garantia de sistema educacional inclusivo, de salas de recursos multifuncionais, classes, escolas ou serviços especializados, públicos ou conveniados (BRASIL, 2014).

Cumpre destacar que o processo de tramitação e aprovação do PNE (2014-2024) mais uma vez foi marcado pela expressão da correlação de forças existentes, historicamente, na definição de políticas da educação especial, reivindicando ou rechaçando a aplicação de recursos públicos na educação especial. Ficou evidente a forte capacidade das entidades especializadas privadas de influenciar os parlamentares na garantia da manutenção do financiamento das instituições comunitárias, confessionais ou filantrópicas sem fins lucrativos por meio de convênios com o Poder Público na oferta de serviços de educação especial.

Assim, na tentativa de analisar a relação existente entre as políticas de educação especial desencadeadas pelo governo federal e o financiamento da educação, buscamos discutir desdobramentos dessas diretrizes para a gestão dos recursos públicos voltados a essa modalidade de ensino em um município brasileiro, buscando problematizar possibilidades de resistência e de acatamento às políticas nacionais em âmbito local.

\section{GESTÃO, TRANSPARÊNCIA E CONTROLE SOCIAL DOS RECURSOS PÚBLICOS DA EDUCAÇÃO ESPECIAL NO MUNICÍPIO DE VITÓRIA}

A educação especial está sob a égide da descentralização do ensino, que historicamente tem sido a forma de gestão da educação no Brasil, "transferindo as competências da esfera central de poder para as locais" (AZEVEDO, 2002, p. 54). Nesse sentido, a educação especial está inserida sob as mesmas normas de organização políticoadministrativa e de gestão previstas para as outras etapas da educação básica e modalidades de ensino. 
Desse modo, está inserida sob a organização de uma República federativa, em que cada ente federado tem suas responsabilidades, no setor educacional, na oferta, no planejamento e no financiamento em suas respectivas áreas de atuação prioritária: os municípios, educação infantil em creche e pré-escolas, e, com prioridade, o ensino fundamental; os estados, o ensino fundamental e, com primazia, o ensino médio; e a União, a organização e o financiamento de órgãos e instituições oficiais do sistema federal de ensino e a prestação de assistência técnica e financeira ao Distrito Federal, aos estados e aos municípios, sendo os três entes também responsáveis pela oferta das modalidades de ensino em suas respectivas áreas de jurisdição (BRASIL, 1988; 1996a).

Nessa perspectiva, tentamos discutir a gestão do financiamento da educação especial no sistema municipal de ensino de Vitória, de modo a analisar o esforço do Poder Público no provimento de recursos financeiros voltados a essa modalidade de ensino, nos anos de 2008 a 2014.

Vitória, capital do Espírito Santo, compõe, juntamente com os municípios de Serra, Cariacica, Viana, Vila Velha, Fundão e Guarapari, a Região Metropolitana da Grande Vitória (RMGV). Segundo o censo populacional de 2010, realizado pelo IBGE, o município cobria uma faixa de $98.194 \mathrm{~km}^{2}$. Em 2010, tinha sua população estimada em 327.801 mil habitantes. E era prioritariamente urbana, composta, em sua maioria, de pessoas em idade ativa entre 15 e 64 anos (72,52\%) (PNUD, 2013). O valor da renda per capita ${ }^{8}$, em 2010, era de R $\$$ 1.866,58 reais (PNUD, 2013).

O sistema municipal de ensino de Vitória, desde a sua criação Lei 4.747, de 27 de julho de 1998(VITÓRIA, 1998), buscou assegurar o direito à educação a todos os cidadãos, mediante a garantia do ensino fundamental e da educação infantil e das modalidades de ensino: educação especial e educação de jovens e adultos. A rede municipal de ensino de Vitória, no ano de 2014, era constituída por 53 unidades de ensino fundamental e 48 unidades de educação infantil. $O$ total do número de matrículas na rede municipal, de acordo com o Censo Escolar de 2014, correspondia a 49.227, sendo 18.436 na educação infantil, 26.788 no ensino fundamental, 1.063 na educação especial (todos na classe comum, representando $2,2 \%$ do total de matrículas) e 2.940 na educação de jovens e adultos (EJA).

O município de Vitória, desde a década de 1990, desenvolveu ações direcionadas ao atendimento ao público da educação especial. Inicialmente, por meio dos Laboratórios Pedagógicos, que oferecia serviços de apoio especializado nas escolas comuns da rede, localizadas 
nas regiões administrativas do município. Depois, reconfigurou a forma de atendimento aos alunos da educação especial, dando ênfase à implantação dos Laboratórios Pedagógicos em diferentes escolas de ensino fundamental e educação infantil. Posteriormente, o atendimento educacional especializado foi redimensionado para as unidades de ensino, a fim de garantir a efetiva oferta desse serviço nas salas de recursos multifuncionais, aprimorar as práticas pedagógicas e disseminar as discussões acerca da educação inclusiva no cotidiano da escola (VITÓRIA, 2007; 2008).

O município de Vitória disponibilizava professores de educação especial para o atendimento educacional especializado, no turno oposto ao do ensino regular (na própria escola), nas áreas de deficiência intelectual, TGD, deficiência física, deficiência visual, na área de surdos e na área das altas habilidades/superdotação, em espaço específico, com o objetivo de atender os interesses dos alunos nas diferentes áreas do conhecimento, com proposta de planos de trabalhos individualizados e/ou coletivos e na busca de parcerias com instituições superiores, técnicas, de esporte, de artes, entre outras (VITÓRIA, 2008). Entretanto, o município não tinha concurso específico para professores de educação especial. Esses professores eram selecionados por meio de um processo interno, do quadro efetivo da Prefeitura Municipal de Vitória (PMV), da educação infantil e do ensino fundamental, ou eram admitidos em regime de contratação temporária (VITÓRIA, 2008c).

O sistema municipal de ensino de Vitória tentava garantir o ensino público à sua população, por meio da oferta da educação infantil, do ensino fundamental, da EJA e da educação especial. Nessa perspectiva, apresentava diversas ações que absorviam recursos e representavam investimento, por parte do Estado, no intuito de efetivar o direito à educação (FRANÇA, 2014).

Ao analisarmos as despesas por subfunção constatamos que o ensino fundamental e a educação infantil absorveram a maior parte dos recursos vinculados a função educação ${ }^{9}$, como poderemos observar na Tabela 1. 
TABELA 1 - Despesas por função e subfunções vinculadas à educação - Vitória/ES 2008 a 2014 (R\$)

\begin{tabular}{|c|c|c|c|c|c|c|c|}
\hline \multirow{2}{*}{ 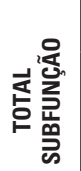 } & \multicolumn{7}{|c|}{ ANO } \\
\hline & 2008 & 2009 & 2010 & 2011 & 2012 & 2013 & 2014 \\
\hline 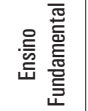 & 182.702.436,21 & $207.727 .678,63$ & $199.057 .334,57$ & 193.136.726,32 & $206.648 .041,95$ & 200.079.111,59 & 199.497.911,58 \\
\hline $\begin{array}{l}\text { 胥 } \\
\text { 恶 } \\
\text { 壳 }\end{array}$ & 129.838.005,49 & $110.607 .714,48$ & $139.978 .229,68$ & $158.517 .143,06$ & $161.102 .033,45$ & $157.525 .393,98$ & $165.545 .615,49$ \\
\hline 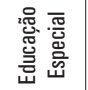 & $732.501,58$ & $458.975,42$ & $345.416,22$ & $120.364,19$ & $233.960,67$ & $230.914,58$ & $548.933,41$ \\
\hline 壱 & 0,00 & 0,00 & $144.750,77$ & $263.699,41$ & $271.109,25$ & $305.642,78$ & $314.925,93$ \\
\hline 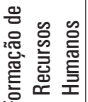 & 0,00 & 0,00 & $25.351,90$ & $1.964,58$ & 0,00 & 0,00 & 0,00 \\
\hline 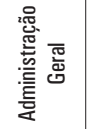 & 3.123.143,12 & $5.575 .888,07$ & $5.000 .604,86$ & $5.991 .667,32$ & $6.580 .726,63$ & $9.289 .009,95$ & 22.068.715,17 \\
\hline 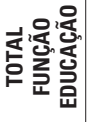 & 316.396.086,40 & $324.370 .256,60$ & $344.551 .688,00$ & 358.031.565,16 & 374.835.871,95 & $367.430 .072,88$ & |387.976.101,59 \\
\hline
\end{tabular}

Fonte: Semfa/Relatório RREO - Demonstrativo da execução das despesas por função e subfunção 2008 a 2014. Elaboração própria. Valores atualizados com base no INPC/IBGE de 12/2015.

Com base nos dados, percebemos que o ensino fundamental em Vitória/ES recebeu em média 56\% dos recursos totais aplicados na educação básica no período de 2008 a 2014. A educação infantil recebeu cerca de $41 \%$. A EJA teve suas despesas registradas em subfunção somente a partir de 2010 e representava em média 0,06\%. 
A educação especial foi mantida com recursos municipais, porém estes representaram em média $0,1 \%$ do total de despesas da função educação, de 2008 a 2014. Cumpre ressaltar que o percentual de matrículas de educação especial na rede municipal de ensino de Vitória nesse período, correspondia a $2 \%$ a 3\% do total de matrículas da educação básica. Nesse sentido, diante desse percentual ínfimo $(0,1 \%)$ questionamos como o município custeou essa modalidade de ensino, uma vez que a existência de matrículas repercute em despesas e pressupõe, por parte do município, investimento para a ampliação de sua oferta e serviços.

Cabe ressaltar que as despesas vinculadas ao funcionamento da parte administrativa da Secretaria de Educação de Vitória e aos espaços não formais da rede municipal considerados como ensino complementar na política de educação do município (Escola de Ciência e Física; Escola da Ciência Biologia e História; o Planetário; e a Praça da Ciência) foram registradas como despesas de subfunções(Administração geral e Formação de Recursos), embora não estivessem agregadas as etapas e modalidades de ensino.

Assim, as informações sobre as despesas por subfunção no município de Vitória possibilitaram conhecer quais eram as etapas e/ ou modalidades enfatizadas na política da rede municipal de ensino de Vitória, no período de 2008 a 2014, ou seja, o ensino fundamental e a educação infantil, representadas nos valores destinados a essas etapas no total de recursos vinculados à função educação. Considerase ainda, a definição da LDB/1996 quanto às competências de cada ente federado pela oferta educacional, na qual cabe ao município o atendimento prioritário na educação infantil e no ensino fundamental.

No que se refere às despesas da educação especial registradas nos balanços da Secretaria Municipal de Educação de Vitória (SemeVitória), evidenciamos que os valores despendidos com pessoal ${ }^{10}$ (Tabela 2) não foram descritos, visto que o município não tinha uma classificação funcional para os profissionais que atuavam na educação especial, como já mencionado. Esse custo estava contido no global da rubrica das etapas de ensino, uma vez que esses profissionais eram oriundos da educação infantil e/ou do ensino fundamental. Cumpre destacar que no ano de 2013, apareceu uma nova especificação destinada à Administração Geral. Essas despesas estavam vinculadas ao funcionamento da parte administrativa da Secretaria de Educação e aos espaços não formais da rede municipal, considerados como ensino complementar na política de educação do município. 
TABELA 2 - Despesas com pessoal por etapas de ensino - Vitória/ES 2008 a 2014 (R\$)

\begin{tabular}{|c|c|c|c|c|c|c|c|}
\hline \multirow{2}{*}{ 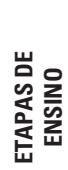 } & \multicolumn{7}{|c|}{ VALORES EM RS } \\
\hline & 2008 & 2009 & 2010 & 2011 & 2012 & 2013 & 2014 \\
\hline 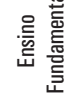 & $137.868 .583,30$ & $174.774 .090,52$ & $153.759 .827,14$ & $152.999 .840,83$ & 174.585.302,45 & 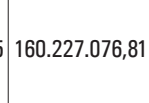 & 158.944.535,01 \\
\hline 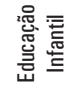 & 105.054.072,84 & 82.823.874,96 & 118.498.058,44 & 141.161.047,14 & 137.617.731,76 & $123.500 .948,18$ & $135.240 .060,19$ \\
\hline 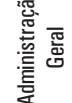 & 0,00 & 0,00 & 0,00 & 0,00 & 0,00 & $5.578 .010,49$ & 11.110.995,17 \\
\hline 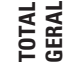 & 242.922.656,14 & 257.597.965,48 & 272.257.885,58 & 294.160.887,97 & 312.203.034,21 & 289.306.035,48 & 305.295.590,37 \\
\hline
\end{tabular}

Fonte: Semfa/Relatório - Demonstrativo de natureza e despesa 2008 a 2014.

Elaboração própria.

Valores atualizados com base no INPC/IBGE de 12/2015.

Os dados da Tabela 2 mostraram que, de 2008 a 2014, as despesas com pessoal no ensino fundamental, representavam, em média, $56 \%$ e,na educação infantil, $43 \%$. Nesse período, podemos observar oscilações nos valores de despesas com pessoal, mas resultando em um aumento percentual relativo de 26\% entre 2008 a 2014.

Em continuação à análise das despesas correntes, dirigidas à manutenção e ao desenvolvimento do ensino, dispomos, na Tabela 3 , as despesas de custeio na educação infantil, ensino fundamental, educação especial e EJA. 
TABELA 3 - Despesas por custeio, por etapas e modalidades Vitória/ES 2008 a 2014 (R\$).

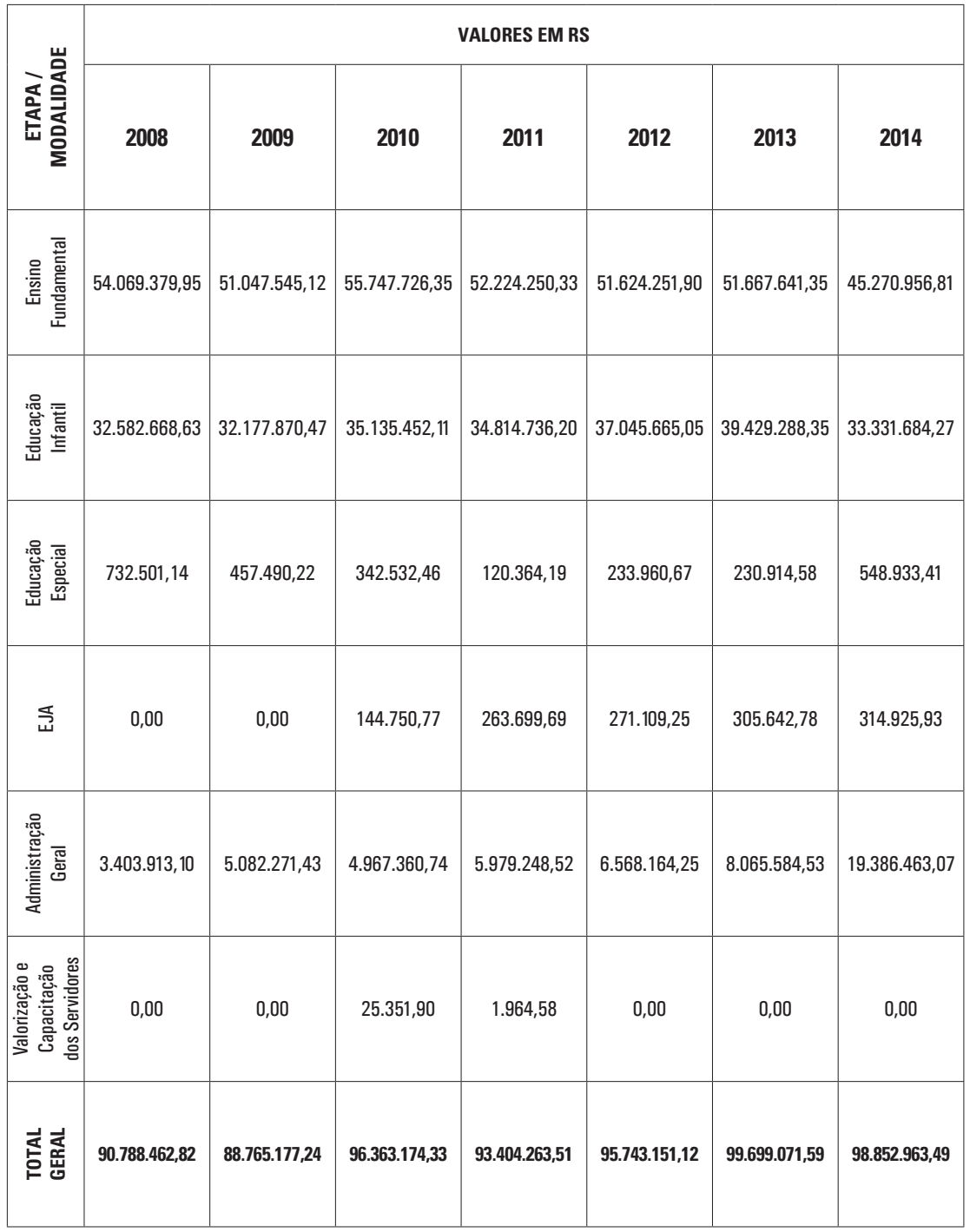

Fonte: Semfa/Relatório - Demonstrativo de natureza e despesa 2008 a 2014. Elaboração própria. Valores atualizados com base no INPC/IBGE de 12/2015. 
Notamos que foi despendido com custeio um total de aproximadamente R \$ 91 milhões em 2008e R $\$ 99$ milhões em 2014 (SEMFA, 2008e 2014), destinados às diferentes etapas e modalidades de ensino, apresentando oscilações nos valores, mas resultando em um aumento percentual relativo de 9\% entre 2008 e 2014 .

A educação especial participou das despesas do custeio da Secretaria, nesse mesmo período, na proporção de aproximadamente $0,4 \%$. Essa constatação poderia nos levar a afirmar, como Prieto e Gil (2011, p. 96), que "o custeio da educação especial não é mais caro, proporcionalmente, do que o custeio das demais etapas e modalidades". Entretanto, o fato de as despesas com pessoal, maior responsável pelos gastos com educação,não terem sido registradas nos demonstrativos do município pode sustentar a hipótese de que os valores de custeio da educação especial podem estar subdimensionados por estarem agregados às outras etapas de ensino; por isso, a comparação dos gastos nessa modalidade de ensino com outras etapas e modalidades torna-se mais difícil e complexa.

Cumpre destacar que a CF/1988 estabelece como princípio constitucional "gestão democrática ao ensino público, na forma da lei” (BRASIL, 1988, art. 206, VI). Esse princípio foi ratificado na LDB/1996, art. 72, no qual também foi destacada a obrigatoriedade do Poder Público de publicizar as informações de arrecadação e despesa em educação, bem como o cumprimento da vinculação de recursos. No caso dos recursos destinados à educação especial, esses também deveriam ser registrados nos relatórios de execução orçamentária e procedimentos contábeis das contas públicas dos respectivos entes federados, no intuito de garantir visibilidade nas receitas e despesas destinadas à manutenção e desenvolvimento da educação e a possibilidade de acompanhamento e controle dos recursos públicos da educação no âmbito do Estado brasileiro.

Em relação às despesas de capital ${ }^{11}$ (Tabela 4), o município não despendeu recursos para compra de equipamentos e materiais permanentes para a educação especial no período analisado, segundo os dados cedidos pela Secretaria Municipal de Fazenda. 
TABELA 4 - Despesas de capital - Vitória/ES 2008 a 2014 (R\$)

\begin{tabular}{|c|c|c|c|c|c|c|c|}
\hline \multirow{2}{*}{ 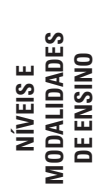 } & \multicolumn{7}{|c|}{ ANO } \\
\hline & 2008 & 2009 & 2010 & 2011 & 2012 & 2013 & 2014 \\
\hline 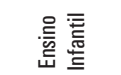 & $6.645 .759,38$ & $8.213 .683,59$ & $8.167 .516,38$ & 13.152.476,63 & $11.335 .150,36$ & $5.239 .562,38$ & $10.620 .299,42$ \\
\hline 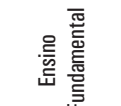 & $10.374 .580,25$ & $5.859 .616,94$ & $6.410 .107,12$ & $10.330 .049,01$ & $17.477 .816,21$ & $14.894 .518,96$ & 16.714.722,71 \\
\hline 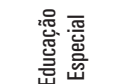 & 0,00 & $1.485,20$ & $2.883,76$ & 0,00 & 0,00 & 0,00 & 0,00 \\
\hline 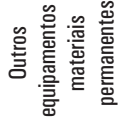 & 0,00 & $1.485,20$ & $2.883,76$ & 0,00 & 0,00 & 0,00 & 0,00 \\
\hline 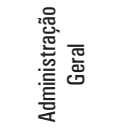 & $15.087,52$ & $39.281,82$ & $33.244,12$ & $12.418,80$ & $12.562,39$ & 0,00 & $1.378,69$ \\
\hline 居志 & $17.035 .427,15$ & 14.114.067,55 & 14.613.751,37 & 23.494.944,44 & 28.825.528,96 & $20.134 .081,34$ & $27.336 .400,82$ \\
\hline
\end{tabular}

Fonte: Semfa/Relatório - Demonstrativo de natureza e despesa 2008 a 2014.

Elaboração própria.

Valores atualizados com base no INPC/IBGE de 12/2015.

Pelos dados da Tabela 4conclui-seque as despesas de capital dessa modalidade só foram registradas em 2009 e 2010, e sua participação foi de $0,01 \%$ e $0,02 \%$, respectivamente. Os valores zerados (2008) ou ínfimos (2009 e 2010) não indicam que o município de Vitória nada tenha investido na educação especial, tendo em vista que as despesas podem ter sido contabilizadas em outras etapas de ensino ou podem ter sido utilizadas verbas de outras fontes que não foram registradas nas despesas de capital. De acordo com Bassi e Camargo (2010, p. 300), 
[...] de forma geral, as gestões municipais permanecem como zonas obscuras e resistentes a sua publicização em função de uma "tradicional forma de gestão", devido a procedimentos de reiteração burocrática da máquina pública; pode-se pensar adicionalmente que a condição de ser opaca permite à administração que os interesses estratégicos (econômicos e políticos) locais se realizem no âmbito do Estado.

Essa necessidade de transparência na gestão dos recursos públicos educacionais foi ratificada no processo de obtenção dos valores financeiros de despesas destinadas à educação especial nas diferentes fontes de informação do governo federal, estadual e municipal. Os dados eram apresentados de forma agregada, o que impossibilitava identificar o que era alocado na educação especial. Assim, embora a rede municipal de ensino de Vitória apresentasse matrículas nessa modalidade de ensino, os valores apresentados pareciam não corresponder às despesas reais com a manutenção da educação especial no município, por estarem agregados aos recursos de outras etapas de ensino, como o ensino fundamental e a educação infantil.

Nessa perspectiva, embora as políticas de educação especial no Brasil apontassem e/ou direcionassem para a continuidade de repartição de responsabilidades quanto à oferta de serviços com a iniciativa privada, representadas pelas instituições privadas de educação especial, o poder público municipal conseguiu desenvolver esforços na tentativa de garantir serviços e atendimento educacional especializado ao público-alvo da educação especial, por meio de profissionais qualificados, atendimento em salas de recursos multifuncionais, formação continuada e outras ações direcionadas ao atendimento aos alunos com deficiência, TGD e altas habilidades/ superdotação no âmbito da escola.

Entretanto, os esforços do município com essa modalidade não são visíveis ou materializados nas contas públicas do município, na forma como foram disponibilizadas para a pesquisa. A análise das despesas mostra que o montante investido na educação especial era ínfimo se comparado às outras etapas de ensino no município, sem a informação desagregada de gastos com pessoal. Esse panorama evidencia que não há possibilidade de identificar, controlar e acompanhar os recursos destinados a essa modalidade senão houver mudanças na forma como são registrados os dados financeiros da educação especial nas contas públicas municipais.

Dessa maneira, consideramos que não se pode monitorar e avaliar uma política de financiamento da educação especial sem informações claras, precisas e pormenorizadas dos recursos alocados para essa modalidade de ensino no âmbito do financiamento da 
educação básica. Assim, faz-se necessário (re)pensar os demonstrativos fiscais dos recursos da educação e criar instrumentos que promovam a visibilidade e a transparência do financiamento dessa modalidade de ensino nos sistemas educacionais.

\section{CONSIDERAC̣̃̃ES FINAIS}

Nessa perspectiva, ao discutir o financiamento da educação especial no município de Vitória-ES, a partir da análise dos esforços do poder público no provimento de recursos para essa modalidade de ensino, no período de 2008 a 2014, destacamos alguns aspectos relacionados à gestão pública das verbas educacionais.

No que se refere à gestão do financiamento da educação especial, quanto à gestão, transparência, organização, padronização e o controle social dos recursos públicos voltados a essa modalidade de ensino, observamos, por meio de dados de um município brasileiro, que sua gestão e financiamento estão imbricados com a educação básica e que a estruturado Estado brasileiro não favorece o acompanhamento, o controle social e a transparência das informações dos recursos públicos aplicados à educação. Essa prática tem se mostrado comum a outros municípios brasileiros, conforme apontado pelos pesquisadores (PRIETO; GIL, 2011; GONZALEZ; PRIETO, 2012) que desenvolveram estudos referentes ao financiamento da educação especial.

Cabe acrescentar que as disparidades nos valores de despesas da educação infantil, ensino fundamental e modalidades de ensino (neste caso, particularmente, educação especial e EJA), nos diferentes órgãos oficiais, dificultam o acompanhamento e o controle dos recursos públicos na área de educação. Isso mostra a necessidade de padronização de procedimentos de envio dessas informações e a criação de uma forma de registros dos gastos, na qual esses gastos estejam desagregados não apenas pelos referentes aos níveis da educação básica e às modalidades de ensino bem como com a declaração do que é referente a custeio e a pessoal e que estes sejam correspondentes aos valores reais aplicados na educação básica. Inclusive dos recursos públicos direcionados às instituições privadas que oferecem serviços de educação especial.

Esse modelo de prestação de contas ainda engendra entraves tantopara agestão da educação especial, noâmbitodaUnião, dos estados e dos municípios, pois torna ainda mais complexo o planejamento e políticas públicas voltadas à garantia dos direitos à educação do público da educação especial; quanto para os pesquisadores (VIEIRA, 
R., 2014; PRIETO; GIL, 2011; GONZALEZ; PRIETO, 2012) que, em particular, desenvolvem estudos referentes ao financiamento da educação especial e de outras modalidades de ensino. Em geral, eles trabalham com estimativas e/ou dados aproximados de gastos e/ou custos destinados ao atendimento às pessoas com deficiência, TGD e altas habilidades/superdotação.

Nessa direção, defendemos que as políticas educacionais, entre as quais a de educação especial, podem se desenvolver sob os parâmetros democráticos, explicitados por Azevedo (2002), com ampla participação política dos diferentes grupos sociais articulados com a luta pelo direito à educação para as pessoas com deficiência, TGD e altas habilidades/superdotação no âmbito dos diferentes espaços públicos, na elaboração das políticas, no planejamento orçamentário e no acompanhamento e controle social dos recursos aplicados na educação com vistas a redimensionar as formas de políticas, gestão e financiamento da educação brasileira.

\section{REFERÊNCIAS}

AMARAL, N. C. Para compreender o financiamento da educação básica no Brasil. Brasília: Lỉber Livro, 2012. AZEVEDO, J. M. L. de. Implicações da nova lógica de ação do Estado para a educação municipal. Educação \& Sociedade, Campinas, v. 23, n. 80, p. 49-71, setembro. 2002.

BASSI, M. E.; CAMARGO, R. B. de. Estilo de gestão da educação municipal: implicações para a gestão democrática e controle social. Revista Brasileira de Política e Administração da Educação, Porto Alegre, v. 26, n. 2, p. 209-408, maio/ago. 2010.

BENAT'TI, M. M. S. O financiamento público das instituições não-estatais de educação especial em Campo Grande - (2001-2005). VI CONGRESSO BRASILEIRO MULTIDISCIPLINAR DE EDUCAÇ̃̃O ESPECIAL E VII ENCONTRO DA ASSOCIAÇÃO BRASILEIRA DE PESQUISADORES EM EDUCAÇÃO ESPECIAL, 6., 2011. Paraná. Anais. Paraná: UEL, p. 3478-3488,2011.

BRASIL. Constituição [da] República Federativa do Brasil. Brasília: Senado Federal, 1988.

BRASIL. Lei de Diretrizes e Bases da Educação Nacional- LDB n9.394, de 20 de dezembro de 1996. Diário Oficial [da] República Federativa do Brasil, Brasília, 23 dez. 1996 a.

BRASIL. Emenda Constitucional n¹4, de 12 de setembro de 1996. Modifica os artigos 34, 208, 211 e 212 da Constituição Federal e da nova redação ao art. 60 do Ato das Disposições Constitucionais Transitórias. Diário Oficial [da] República Federativa do Brasil. Seção 1, p. 18109,13 set. 1996 b.

BRASIL. Lei no 9.424, de 24 de dezembro de 1996. Dispõe sobre o Fundo de Manutenção e Desenvolvimento do Ensino Fundamental e de Valorização do Magistério. Diário Oficial [da] República Federativa do Brasil, Seção 1. Brasília, 26 dez. 1996 c.

BRASIL. Lei Complementar no 101, de 4 de maio de 2000. Estabelece normas de finanças públicas voltadas para a responsabilidade na gestão fiscal e dá outras providências. Diário Oficial [da] República Federativa do Brasil, Brasília, 4 maio 2000. 
BRASIL. Conselho Nacional de Educação. Câmara de Educação Básica. Resolução CNE/ CEB no 2, de 11 de setembro de 2001. Diretrizes Nacionais para a Educação Especial na Educação Básica. Diário Oficial [da] República Federativa do Brasil, Seção 1E, p. 39-40. 14 set. 2001.

BRASIL. Ministério Público Federal. O acesso de alunos com deficiência às escolas e classes comuns da rede regular de ensino. Brasília: Procuradoria Federal dos Direitos do Cidadão, 2004a.

BRASIL. Lei no 10.845 , de 5 de março de 2004. Institui o Programa de Complementação ao Atendimento Educacional Especializado às Pessoas Portadoras de Deficiência, e dá outras providências. Diário Oficial [da] República Federativa do Brasil, Seção 1, p. 1. Brasília, 8 mar. 2004b.

BRASIL. Decreto $\mathrm{n}^{\circ} 5.374$, de 17 de fevereiro de 2005. Fixa, para o exercício de 2005, o valor mínimo anual por aluno de que trata o art. $6^{\circ}, \$ 1^{\circ}$, da Lei $n^{\circ} 9.424$, de 24 de dezembro de 1996 , e dá outras providências. Diário Oficial [da] República Federativa do Brasil, Brasília, 18 fev. 2005a.

BRASIL. Ministério da Fazenda. Secretaria do Tesouro Nacional. Receitas públicas: manual de procedimentos: aplicado à União, Estados, Distrito Federal e Municípios. Brasília: Secretaria do Tesouro Nacional, 2005b.

BRASIL. Emenda Constitucional n. 53, de 19 de dezembro de 2006. Dá nova redação aos art. 7, 23, 30, 206, 208, 211 e 212 da Constituição Federal e ao art. 60 do Ato das Disposições Constitucionais Transitórias. Diário Oficial [da] República Federativa do Brasil, Seção 1, p. 5. Brasília, DF, 20 dez. 2006a.

BRASIL. Lei n 11.494, de 20 de junho de 2007. Regulamenta o Fundo de Manutenção e Desenvolvimento da Educação Básica e de Valorização dos Profissionais da Educação FUNDEB, de que trata o art. 60 do Ato das Disposições Constitucionais Transitórias; altera a Lei $\mathrm{n}^{\circ}$ 10.195, de 14 de fevereiro de 2001; revoga dispositivos das Leis $\mathrm{n}^{\circ} 9.424$, de 24 de dezembro de 1996, nº10.880, de 9 de junho de 2004, e nº10.845, de 5 de março de 2004; e dá outras providências. Diário Oficial [da] República Federativa do Brasil, Brasília, 21 jun. 2007a.

BRASIL. Decreto n ${ }^{\circ}$ 6.253, de 13 de novembro de 2007. Dispõe sobre o Fundo de Manutenção e Desenvolvimento da Educação Básica e de Valorização dos Profissionais da Educação FUNDEB, regulamenta a Lei n¹1.494, de 20 de junho de 2007, e dáoutras providências. Diário Oficial [da] República Federativa do Brasil, Seção 1, p. 18. Brasília, 14 nov. 2007 b.

BRASIL. Política Nacional de Educação Especial na Perspectiva da Educação Inclusiva. Brasil: MEC/ SEESP, 2008a.

BRASIL. Decreto n ${ }^{\circ}$ 6.571, de 17 de setembro de 2008. Dispõe sobre o atendimento educacional especializado, regulamenta o parágrafo único do art. 60 da Lei no 9.394, de 20 de dezembro de 1996, e acrescenta dispositivo ao Decreto $\mathrm{n}^{\circ} 6.253$, de 13 de novembro de 2007. Diário Oficial [da] República Federativa do Brasil, Seção 1, p. 26. Brasília, 18 set. 2008b..

BRASIL. Conselho Nacional de Educação. Câmara de Educação Básica. Resolução CNE/ CEB n ${ }^{\circ} 4$, de 2 de outubro de 2009. Diretrizes operacionais para o atendimento educacional especializado na educação básica, modalidade educação especial. Diário Oficial [da] República Federativa do Brasil, Seção 1, p. 17. 5 out. 2009.

BRASIL. Decreto n ${ }^{\circ}$ 7.611, de 17 de novembro de 2011. Dispõe sobre a educação especial, o atendimento educacional especializado e dá outras providências. Brasília: Presidência da República, 2011. Diário Oficial [da] República Federativa do Brasil, Seção 1, p. 12. Brasília, 18 nov. 2011.

BRASIL. Senado Federal. Projeto de Lei da Câmara n¹03, 25 de outubro de 2012. Aprova o Plano Nacional de Educação PNE e dá outras providências. Disponível em: <http://www.senado. gov.br/atividade/materia/detalhes.asp?p_cod_mate=108259>. Acesso em: 20 out. 2013. 
BRASIL. Lei n ${ }^{\circ}$ 2.796, de 4 de abril de 2013. Diário Oficial [da] República Federativa do Brasil, Seção 1, p. 1. Brasília, 4 abr. 2013.

BRASIL. Lei nº 13.005, 25 de junho de 2014. Aprova o Plano Nacional de Educação - PNE e dá outras providências. Diário Oficial [da] República Federativa do Brasil, Seção 1, p.1. Brasília, 26 jun. 2014.

BRASIL. Ministério da Educação. Orientações para implementação da política de educação especial na perspectiva da educação inclusiva. Brasilia, 2015. Disponível em: < http:/ /www.pmpf.rs.gov.br/servicos/ geral/files/portal/Documento_Subsidiario_EducaCao_Especial.pdf>. Acesso em: 10 jul. 2015.

BUENO, J. G. S. As políticas de inclusão escolar: uma prerrogativa da educação especial? In: BUENO, J. G.; MENDES, G.; SANTOS, R. (org.). Deficiência e escolarização: novas perspectivas de análise. Araraquara, SP: Junqueira \& Marin; Brasília, DF: CAPES, 2008.

BUENO, C. C.; KASSAR, M. de C. M. Público e Privado: a educação especial na dança de possibilidades. In: ADRIÃO, T.; PERONI, V. O Público e o privado na educação: interfaces entre estado e sociedade. São Paulo: Xamã, 2005.

CARDOSO, D. G. M. Custos da educação especial: análise comparativa do custo/aluno em escola da rede municipal do Rio de Janeiro. 1997. Dissertação (Mestrado em Educação) Programa de Pós-Graduação em Educação, Universidade Católica de Brasília, Brasília, 1997.

CASTRO, J. A. de. Financiamento e gasto público da educação básica no Brasil e comparações com alguns países da OCDE e América Latina. Educação \& Sociedade, Campinas, v. 26, n. 92, p. 841-858, out. 2005.

CORRÊA, N. M. O financiamento da educação especial na rede municipal de ensino de Campo Grande - MS (1998-2006). In: SEMINÁRIO NACIONAL DE PESQUISA EM EDUCAÇÃO ESPECIAL, 4., 2008, Rio Grande do Sul. Anais. Rio Grande do Sul: UFES, UFRGS, CD-ROM, p. 1-11, 2008.

CRUZ, F. da, et al. Comentários à Lei no. 4.320. $2^{\mathrm{a}}$ ed. São Paulo: Atlas, 2001.

DOURADO, L. F. Políticas e gestão da educação básica no Brasil: limites e perspectivas. Educação \& Sociedade, Campinas, n. 100, p. 921-946, out. 2007.

FARENZENA, N. A política de financiamento da educação básica: rumos da legislação brasileira. Porto Alegre, RS: UFRGS, 2006.

FERREIRA, J. R. Políticas públicas, educação especial e inclusão escolar. In: SEMINÁRIO DE EDUCAÇÃO INCLUSIVA, 9. Vitória. Anais. Vitória, ES: UFES, p. 61-64, 2005.

FERREIRA, J. R. Financiamento da educação básica: o público e o privado na educação especial brasileira. In: FÁVERO, O.,et. al. Tornar a educação inclusiva. Brasília: UNESCO, p. 55-64, 2009.

FRANÇA, M. G. Financiamento da educação especial: complexas tramas, permanentes contradições e novos desafios. 2014. Tese (Doutorado em Educação) - Programa de PósGraduação da Faculdade de Educação, Universidade de São Paulo, São Paulo, 2014.

GARCIA, R. M. C.; MICHELS, M. H. A política de educação especial no Brasil (19912011): uma análise da produção do GT15 - educação especial na Anped. Revista Brasileira de Educação Especial. Marília, v. 17, p. 105-124, maio/ago. 2011.

GOMES, C. A.; SOBRINHO, J. A. Educação Especial no Brasil: perfil do financiamento e das despesas. Brasília: MEC/SEEP/UNESCO, 1996.

GONZALEZ, R. K.; PRIETO, R. G. Financiamento da educação especial em município paulista: algumas aproximações com o tema. In: V CONGRESSO BRASILEIRO DE 
EDUCAÇÃO ESPECIAL E VII ENCONTRO NACIONAL DOS PESQUISADORES DA EDUCAÇÃO ESPECIAL, V, 2012, São Carlos, Anais. São Carlos: UFSCar, p. 7475-7488, 2012.

KASSAR, M. de C. M. Reforma do Estado e Educação Especial: preliminares para uma análise. Revista de Educação PUC-Campinas, Campinas, n. 11, p. 24-34, nov. 2001.

LAPLANE, A. L. F.; PRIETO, R. G. Inclusão, diversidade e igualdade na Conae 2010: perspectivas para o novo Plano Nacional de Educação. Educaşão \& Sociedade, Campinas, v. 31, n. 112, p. 919-938, jul./set. 2010.

MAZZOTTA, M. J. da S. Educaşão Especial no Brasil: história e políticas públicas. São Paulo: Cortez, 2011.

OLIVEIRA, R. P. de. O financiamento da educação. In: OLIVEIRA, R. P. de; ADRIÃO, T. (org.). Gestão Financiamento e direito à Educação: análise da Constituição Federal e da LDB. $3^{\text {a }}$ ed. São Paulo: Xamã, p.83-122, 2007.

PINTO, J. M. de R. ; ADRIÃO, T. Noções Gerais sobre Financiamento da educação. Eccos: revista científica, São Paulo: Centro Universitário Nove de Julho, v. 8, n. 1, p. 23-46, jan./jun. 2006.

PNUD, 2013. Programa das Nações Unidas para o desenvolvimento, Atlas do Desenvolvimento Humano no Brasil. Disponível em:<http://www.pnud.org.br>. Acesso em: 6 abr. 2014.

POLO, J. C. Planejamento e orçamento no município. In: PRASEM, FUNDESCOLA, MEC. Guia de consulta. Brasília: MEC, p. 295-329, 1999.

POULANTZAS, N. As classes sociais no capitalismo de hoje. Rio de Janeiro/RS: Zahar, 1975.

POULANTZAS, N. Poder Político e classes sociais. 2ed. São Paulo/SP: Martins Fontes, 1977.

POULANTZAS, N. O Estado, o poder, o socialismo. São Paulo: Paz e Terra, 2000.

PRIETO, R. G. Gestão das políticas de atendimento aos alunos com necessidades educacionais especiais em municípios paulistas. In: IX ENCONTRO DE PESQUISA EM EDUCAÇÃO DA REGIÃO SUDESTE, IX, 2009, São Carlos. Anais. São Carlos: UFSCar, 2009, CD-ROM. p. 1-9.

PRIETO, R. G.; GIL, I-Juca-Pirama C. Gestão das politicas de atendimento aos alunos com necessidades educacionais especiais em municípios paulistas. Relatório de Pesquisa. São Paulo: Faculdade de Educação - USP, 2011.

VIEGAS, L. T.; BASSI, M. E. A educação especial no âmbito da política de fundos no financiamento da educação. Reflexão e ação, Santa Cruz do Sul, v. 17, p. 54-87, 2009.

VIEGAS, L. T. A reconfiguração da educação especial e os espaços de atendimento educacional especializado: análise da constituição de um centro de atendimento em Cachoeirinha/RS. 2014. Tese (Doutorado em Educação) - Programa de Pós-Graduação em Educação, Universidade Federal do Rio Grande do Sul, Porto Alegre, 2014.

VIEIRA, R. Expectativas e frustrações: a inclusão da EJA no Fundeb. In: II ENCONTRO DA ASSOCIAÇÃO DE PESQUISA EM FINANCIAMENTO DA EDUCAÇÃO, 2.,2014. Paraná. Anais. Paraná: UFPR, p. 94-10, 20148.

VIEIRA, S. L.; ALBUQUERQUE, M. G. M. Política e planejamento educacional. $3^{a}$ ed. Fortaleza: Edições Demócrito Rocha/EdUECE, 2002.

VIEIRA, S. L.; ALBUQUERQUE, M. G. M. Educaşão Básica: política e gestão da escola. Brasília: Liber Livro, 2009.

VITÓRIA. Plano de Trabalho-2007/2008/2009. Vitória, ES: SEME/SPP/CFAEE Coordenação de Formação e Acompanhamento à Educação Especial, 2007. 


\section{NOTAS}

${ }^{1}$ Para Poulantzas (1975, p. 14) as classes sociais "são conjuntos de agentes sociais determinados principalmente, mas não exclusivamente, por seu lugar no processo de produção, isto é, na esfera econômica" e "[...] define-se pelo seu lugar no conjunto das práticas sociais, isto é, pelo seu lugar no conjunto da divisão social do trabalho, que compreende as relações políticas e as relações ideológicas”. Desse modo, classe social envolve também as relações político-ideológicas.

2 As frações de classes correspondem às camadas sociais que se situam, embora de maneira desigual, no âmbito do Estado, tais como: a aristocracia operária, as cúpulas da burocracia e da administração, a burguesia nacional, industrial, comercial e financeira, entre outros (POULANTZAS, 1977).

${ }^{3}$ Programa Educação Inclusiva: direito à diversidade (2003); Programa Implantação de Salas de Recursos Multifuncionais (2007); Programa Incluir (2005); Programa Escola Acessível (2007) e Programa Benefício da Prestação Continuada da Assistência Social - BPC na escola (2007).

${ }^{4}$ Inclusão escolar entendida como "uma proposição política em ação, de incorporação de alunos tradicionalmente têm sido excluídos da escola" (BUENO, 2008, p. 49), como aconteceu com o atual público-alvo da educação especial.

${ }^{5}$ Segundo o "Manual de Procedimentos da Receita Pública", da Secretaria do Tesouro Nacional, Receita Tributária "são os ingressos provenientes da arrecadação de impostos, taxas e contribuições de melhoria. Dessa forma, é uma receita privativa das entidades investidas do poder de tributar: União, Estados, Distrito Federal e os Municípios” (BRASIL, 2005b, p. 17).

${ }^{6}$ Fundo criado no âmbito de cada estado e do Distrito Federal, composto de 15\% da arrecadação de quatro impostos e transferências constitucionais (Fundo de Participação dos Estados -FPE; Fundo de Participação dos Municípios - FPM; Imposto sobre Operações relativas à Circulação de Mercadorias e sobre Prestação de Serviços de Transporte Interestadual e Intermunicipal e de Comunicação - ICMS; Imposto sobre Produtos Industrializados, proporcional às exportações - IPI-Exp; e Ressarcimento pela Desoneração de Exportações, de que trata a Lei Complementar no 87, de 13 de setembro de 1996, chamada Lei Kandir). Esse fundo tinha como finalidade "redistribuir os seus recursos dentro do próprio Estado. Portanto, o efeito, dentro de um Estado, é o de retirar os recursos de alguns municípios e os remeter para outros, de tal modo que uniformiza, em todo o Estado o valor aplicado por estudantes do ensino fundamental" (AMARAL, 2012, p. 132).

${ }^{7}$ O Programa tinha como finalidade garantir a universalização do atendimento educacional especializado aos "educandos portadores de deficiência" e sua progressiva inserção em classes comuns do ensino regular, por meio de assistência financeira às entidades privadas sem fins lucrativos que ofereciam serviços gratuitos na modalidade de educação especial (BRASIL, 2004b).

${ }^{8}$ Rendimento mensal total domiciliar per capita nominal em 2010 (PNUD, 2013).

${ }^{9}$ A despesa por função corresponde ao maior nível de agregação das diversas áreas de despesas que competem ao setor público, com a finalidade de especificar em que campo a ação governamental será realizada (como exemplos: educação, saúde, trabalho, cultura, entre outras funções). A despesa por subfunção representa um nível de agregação inferior à função e deve evidenciar a área de atuação do governo, por intermédio da junção de determinado subconjunto de despesas em torno das funções (no caso da função educação, as subfunções são: educação infantil, ensino fundamental, ensino médio, educação profissional, ensino superior, educação especial e EJA) (POLO, 1999). 
${ }^{10}$ Despesas com pessoal referem-se aos recursos relativos à remuneração dos funcionários públicos do setor e aos encargos sociais pagos pela administração, como as obrigações patronais(BRASIL, 2000).

${ }^{11}$ Despesas de capital se referem aos gastos governamentais, “[...] com a intenção de adquirir ou construir bens de capital que contribuirão para a produção ou geração de novos bens e integrarão o patrimônio público" (CRUZ et al., 2001, p. 28).

Submetido: 03/09/2016

Aprovado: 01/09/2017

Contato:

Marileide Gonçalves França

Universidade Federal do Espírito Santo (UFES)

Alto Universitário, caixa postal 96, s/n - Guararema

Alegre $|\mathrm{ES}|$ Brasil

CEP 29.500-000

Rosângela Gavioli Prieto

Faculdade de Educação

Universidade de São Paulo

Cidade Universitária

São Paulo|SP|Brasil

CEP 05.508-040 